\title{
Paying for others' protection: Causal evidence on wages in a two-tier system*
}

\author{
Mário Centeno \\ Banco de Portugal \& ISEG - U. Técnica \& IZA \\ mcenteno@bportugal.pt
}

\author{
Álvaro A. Novo \\ Banco de Portugal \& U. Lusófona \& IZA \\ anovo@bportugal.pt
}

April 2, 2013

\section{PRELIMINARY VERSION}

\begin{abstract}
Mandated employment protection reduces wages of workers by shifting both the demand and supply schedules. In a segmented labor market, a reform of employment protection is expected to have an asymmetric impact on wages of entry and incumbent jobs. We explore a reform that increased the employment protection of open-ended contracts for a well-defined subset of firms (treated), while leaving it unchanged for other firms (control). The causal evidence obtained with this quasi-experiment points to a reduction in wages for new open-ended and fixed-term contracts and no impact on wages of more tenured workers. The reductions estimated for entrants are on the -0.7 to -0.5 percentage points range. This result is consistent with a high degree of substitution between open-ended and fixed-term contracts and a high flexibility of wages of new matches. The impact on wages is heterogeneous across sectors and worker characteristics, such as gender, age, and skills.
\end{abstract}

Keywords: Wages; Two-tier systems; Quasi-experiment; Employment protection

JEL Codes: J31; J32; J63.

${ }^{*}$ We acknowledge the financial support provided by FCT's grant PTDC/EGE-EC0/112177/2009. Opinions expressed herein do not necessarily reflect the views of the Banco de Portugal. Any errors are the responsibility of the authors. 


\section{Introduction}

Two-tier labor markets affect a large proportion of the labor force in European economies. Nowadays, 16 percent of total salaried workers in the Euro area have a temporary contract, with the highest figures in Spain and Portugal (25 and 23 percent, respectively according to the Eurostat). The degree of employment protection affects the level and return to investment in human capital and, therefore, the economic growth of nations. It is of utmost importance for policy makers to understand the consequences of partial reforms that lead to two-tier systems. How does a two-tier reform affect wages? Who pays for workers' protection? We answer these questions in the context of a reform of the Portuguese Labor Code that generated a quasiexperiment, showing that wages respond asymmetrically to the two-tier nature of the reform.

The most simple economic models claim that there are no free lunches and workers will pay for their own protection. In competitive markets, Lazear (1990) shows that the cost of protection will be transmitted to workers in the form of lower wages. This question gains an extra degree of complexity in two-tier systems because protected open-ended contracts coexist with more flexible fixed-term arrangements (Boeri 2010). Two-tier systems have become ubiquitous in European countries in the last couple of decades. Rather than flexing the rules governing open-ended contracts, labor market reforms increased the protection gap between incumbents (on open-ended contracts) and entry jobs (mostly on fixed-term contracts). But increasing the employment protection of open-ended may generate a substantial spillover on the other segment. Boeri (2010) predicts an increase in the wage premium of incumbents over entry jobs. The insider-outsider bargaining model of Lindbeck and Snower (2001) argues that incumbent workers enjoy a larger bargaining power and will use it to avoid the cost of the extra protection. On the contrary, the model predicts that movers, under new contracts (either open-ended or fixed-term), with lower bargaining power will pay a larger share of the total cost of the extra protection of stayers.

Our analysis contributes to the growing literature on two-tier labor markets that dates back to the work by Abowd, Corbel and Kramarz (1999) and has been extended by Bentolila, Cahuc, Dolado and Le Barbanchon (2010), Boeri (2010), and Cahuc, Charlot and Malherbet (2012). However, establishing a causal relationship between employment protection and wages has been a major challenge for the empirical literature. We overcome this by exploring a reform of the Portuguese Labor Code implemented in 2004. The reform increased the protection of open- 
ended employment for firms with 11 to 20 workers (our treatment group), but left it unchanged for all other firms (we use firms with 21 to 50 workers as a control group). The generated quasi-experimental setting is propitious for causal inference of two-tier employment protection legislation. We use an administrative matched employee-employer dataset - Quadros de Pessoal - covering all private sector matches, for the 2002 to 2008 period. The dataset covers more than 3.1 million match $\times$ year observations.

In this setting, we ask if wages in the Portuguese labor market reacted to the tighter employment protection. The difference-in-differences estimates indicate that wages in treated firms fell significantly. This is true for base wages, but also for total compensation and their hourly counterparts. In the context of two-tier reforms, we obtained a large fall in total wages of fixed-term contracts in treated firms (around 0.6 percentage points), whereas wages of open-ended workers decreased by 0.2 percentage points. But we should differentiate the impact on new open-ended contracts (the movers) and existing open-ended contracts (the incumbents). The former have wage losses that are close to those observed for fixed-term contracts whereas incumbents have their wages almost unchanged. Our results confirm the predictions of Boeri (2010) matching model and Lindbeck and Snower (2001) bargaining model. Increased employment protection results in a larger wage premium of incumbent open-ended contracts. In a segmented labor market, firms shift the cost of employment protection to the less protected segment, circumventing - however inefficiently - part of the effects of the extra rigidity. The new cohort of permanent jobs will pay for the extra protection and the unchanged wage level of incumbent workers can be interpreted as a sign of nominal wage rigidity typical of all incentive models of the labor market, as the ones of internal labor markets at the firm level (Doeringer, Piore et al. 1971).

But the impact on wages is far from homogeneous. Not surprisingly, sectors traditionally less unionized and also less prone to returns to specific human capital - construction and services - adjusted wages downward more than the manufacturing sector. Male workers, with a more inelastic labor supply, suffer a larger wage loss, whereas females have their wages unchanged by the more stringent employment protection. Also, older workers, with higher bargaining power, tend to lose less, as do white collar workers in new contracts. Our results are robust to a battery of treatment and sample definitions. 


\section{The reform of employment protection}

The Portuguese labor market is an extreme case of a two-tier system. In this section, we provide an overview of its characteristics, along with a description of a reform that increased the employment protection gap between open-ended and fixed-term contracts. This reform provides the quasi-experimental setting used to analyze the impact on wages of employment protection.

\subsection{The 2004 reform: More protection for open-ended contracts}

In Portugal, fixed-term contracts were introduced in 1976, but its usage has been gaining importance. In the last decade, there was a large increase in the share of fixed-term contracts among salaried employment - in 2002, they represented almost 20\%, increasing to more than $27 \%$ in 2008 . They are offered concurrently with open-ended contracts because there are no major legal restrictions on temporary hiring. The Labor Code makes them legal (and economic) substitutes.

These features are not exclusive of Portugal. The introduction of fixed-term contracts was common in other European labor markets. The perception of a strong protection of openended contracts led to the introduction of fixed-term contracts, with lower dismissal costs, mostly procedural, but also in financial terms (Boeri 2010). However, according to the OECD employment protection legislation indicator, Portugal has one of the largest protection gaps between the two type of contracts. These features of the Portuguese labor market make it well-suited to analyze the relationship between wages and employment protection.

The differences in severance payments for permanent and fixed-term contracts are minor. The largest contribution to the gap resides in the procedural costs to terminate a match, which are absent at the expiration of fixed-term contracts, but are rather significant for permanent positions. Firing a worker implies written procedures and witnesses interviews involving the works council and, if the worker is a union delegate, the union itself. Altogether, the procedures extend the dismissal process substantially, typically 2 months, involving legal counselors and administrative costs. Often, to avoid the costs of long and uncertain judicial processes, firms reach out-of-court agreements with the worker. Not surprisingly, these settlements typically exceed the amount legally required.

In 2004, a labor market reform increased the procedural costs for a subset of firms, gener- 
ating a quasi-experimental setting. Before the reform, the law exempted firms with less than 21 workers from the legal procedures listed above. The reform of the labor code changed this threshold to 11 workers (Decreto-Lei 99/2003). The protection gap between open-ended and fixed-term contracts widened for a subset of firms (11 to 20 workers), but remained the same for all other firms. Even though the costs of the procedural requirements are not explicitly defined in the legislation, firms incorporate these expected costs and may adjust wages accordingly.

In the quasi-experimental setting, firms with 11 to 20 workers constitute the treatment group; firms with 21 to 50 workers, a subset of those not affected by the reform, constitute the control group. The firm-size restrictions follow, among others, Burgess, Lane and Stevens (2001), Kugler and Pica (2008), Martins (2009). The specific choice of the threshold was also meant to guarantee a common trend between treatment and control units in the before period.

For the identification strategy required by the difference-in-differences estimator, it is worth mentioning that this reform of the employment protection legislation was part of a more encompassing revision of the Labor Code, which may cast questions over the causal interpretation of the results. For instance, the maximum duration of fixed-term contracts was extended from 3 to 6 years. However, such revisions were not specific to the firm size. Following the differencein-differences identification assumption, these changes, as well as other economic changes, are assumed to affect equally treatment and control groups, canceling in the conditional differencing. However, we do not just assume similarities between the treatment and control firms. We guarantee that there is a common trend between the two groups. Additionally, we perform several robustness checks and test extensively the sensitivity of our results to the specific choice of the treatment and control groups.

\section{$2.2 \quad$ Expected impact on wages}

In the competitive equilibrium, with risk neutral workers, a government-mandated transfer in the form of higher employment protection is completely offset by an initial transfer from the worker to the firm (Lazear 1990). Later, the worker receives the same amount either as higher wages or as a severance payment. However, if there are restrictions to these transfers (e.g. liquidity constraints), such Coasean solutions are not available and the overall impact on wages is negative. The increase in employment protection shifts labor demand inward and creates a deadweight loss, as part of the dismissal costs to the firms are not recouped by the workers, and firms are not able to maintain profits at the previous level. In addition, if the extra protection 
is valued by workers, labor supply will shift outward and wages fall further (Summers 1989).

In a two-tier labor market, Boeri (2010) predicts that an increase in the employment protection for open-ended workers will increase their wage premium over fixed-term workers. The impact on wages reflects the reduction in the conversion of temporary matches into permanent ones, the increase in the destruction rate of fixed-term contracts and the reduction in the job loss rate of permanent contracts. The model does not offer a clear prediction about the impact on the wage level of permanent and temporary matches separately, but only on the widening of the wage gap. The result rests on the assumption of substitutability between the two contracts. If, instead, these matches are poor substitutes, the impact may be tamed.

The Lindbeck and Snower (2001) bargaining model predicts also a larger wage gap. With dismissal threats more costly, firms lose bargaining power over incumbent workers, leading to higher wages for open-ended contracts.

In firms subject to strict employment protection, theory predicts an overall increase in the wage gap. The role played by each type of contract in the ability of firms to adjust employment and wages results in asymmetric adjustments across contracts.

\section{Data}

We use an annual administrative employer-employee dataset, Quadros de Pessoal, which reports, with respect to October of each year, all private sector employment in Portugal. Our analysis starts in 2002, the first year for which the information on the type of contract is available, and ends in 2008, to avoid the influence of the 2009 Labor Code revision. We have two years prior to the reform, 2002 and 2003, and five years after the reform, 2004-2008. Quadros de Pessoal have very detailed firm, worker and match data and been extensively used in the microeconomic analysis in Portugal (e.g. Cabral and Mata 2003, Martins, Solon and Thomas 2012).

The sample includes matches in firms with 11-50 workers. Additionally, we restrict it to workers aged between 15 and 65 years old. We also dropped matches with less than 85 hours or more than 215 hours of work per month, because a standard full-time job has a regular 8-hour working day, 5 days a week. Matches with wages below the minimum wage and above the 99th percentile of the wage distribution were excluded. All observations were checked for longitudinal consistency of time invariant information and have valid information for the 
variables included in the estimation.

Table 1 presents summary statistics for the sample of treatment and control workers. There are a total of 1,405,800 matches (worker $\times$ firm pairs), resulting in an unbalanced panel with $3,581,305$ observations (match $\times$ year pairs). These matches are spread over 56,680 firms and $1,302,865$ workers. In the before period there are 372,770 treatment observations and 513,638 control observations. In the after period there are 1,128,155 treatment observations and 1,566,742 control observations. The average share of fixed-term contracts is $25.8 \%$, a figure similar to the average of the private sector of the economy. Average tenure is 84 months, but with a large standard deviation, 88 months. This hints at the two-tier characteristic of the labor market, with long spells of highly protected employment coexisting with an increasing share of short-term matches. Another characteristic of the Portuguese labor market is the low level of schooling, close to $50 \%$ of workers have 6 or less years of education. Consequently, the average nominal base wage is close to 657 euros (the average minimum wage in this period is 347 euros), below the average for the economy, but conforming with the positive firm size wage premium.

[TABLE 1 (see page 21)]

\section{Difference-in-differences estimator}

\section{Unconditional estimator}

To identify the causal treatment effect, we use a standard difference-in-differences model (Meyer 1995). Let $Y_{i t}^{\text {Treat }}$ be the outcome of interest for individual $i$ at time $t$ in state Treat, where Treat $=1$ if in a treated firm, and 0 otherwise. Due to the fact that, at time $t$, individual $i$ cannot be in both states, the individual treatment effect, $Y_{i t}^{1}-Y_{i t}^{0}$ cannot be computed. However, with an appropriate control group, the difference-in-differences overcomes this limitation by comparing the average behavior before and after the legislative change for the treatment group with the before and after outcomes for the control group.

The identification requires that the average outcomes for treated and controls would have followed parallel paths over time in the absence of the treatment; this assumption is known as the common trend:

$$
E\left[Y_{i t}^{0}-Y_{i t^{\prime}}^{0} \mid \text { Treat }=1\right]=E\left[Y_{i t}^{0}-Y_{i t^{\prime}}^{0} \mid \text { Treat }=0\right]
$$


where $t^{\prime}$ is a time period before the new legislation.

If the assumption expressed in equation (1) holds, the average treatment effect on the treated can be estimated by the sample analogues of

$$
\left\{E\left[Y_{i t} \mid \text { Treat }=1\right]-E\left[Y_{i t} \mid \text { Treat }=0\right]\right\}-\left\{E\left[Y_{i t^{\prime}} \mid \text { Treat }=1\right]-E\left[Y_{i t^{\prime}} \mid \text { Treat }=0\right]\right\},
$$

where $Y_{i t}$ is the observed outcome for individual $i$ at time $t$. If treated and control groups are not balanced in covariates, which may occur often in quasi-experimental settings, the difference-indifferences set-up can be extended to accommodate a set of covariates, and the average impact estimated with a linear regression model (Angrist and Pischke 2009).

\section{Conditional estimator}

In our empirical setting, we estimate the following conditional difference-in-differences model:

$$
\log \left(y_{i t}\right)=\psi_{1} \text { Treat }_{i t}+\psi_{2} \text { After }_{i t}+\psi_{3} \text { After }_{i t} \times \text { Treat }_{i t}+X_{i t} \beta+\varepsilon_{i t},
$$

where $y_{i t}$ is one of four possible outcomes for the wage of worker $i$ at time $t$ : (a) monthly base wage; (b) hourly base wage; (c) monthly total wage; or (d) hourly total wage. After $i t$ is a dummy variable taking value one for the period after the reform, 2004 to 2008, and zero for the period before the reform, 2002 and 2003. In this first estimation, the treatment indicator, Treat $_{i t}$, is defined for each period $t$, and equals 1 for the treatment group (matches in firms with 11-20 workers) and 0 for the control group (matches in firms with 21-50 workers). Later, we will consider different definitions of the treatment and control groups. Consequently, the interaction term, After $_{i t} \times$ Treat $_{i t}$, identifies the causal average treatment effect on the treated due to the policy change.

Despite limiting our study to firms with 11 to 50 workers, there are elements of heterogeneity that we control for with a set of firm, worker and match characteristics. The firm characteristics included in matrix $X_{i t}$ are: (i) the logarithm of the number of workers as a proxy for firm size, (ii) the firm age (indicator variables: $1,2, \ldots, 10,11-15,16-20$, and more than 20 years), (iii) the sector of activity (at 2-digits), (iv) the region (the 23 Portuguese districts), and (v) an indicator of foreign ownership majority. On the worker side, we control for: (vi) gender, (vii) nationality, (viii) age, entering as a quadratic polynomial, and also for (ix) five levels of education (4 or less 
years; 6 years; 9 years; high school; and college degree). In terms of match characteristics, we control for: (x) white and blue collar positions, (xi) workers on a (regulated) minimum wage, with an indicator variable, and for (xii) tenure, entering as a quadratic polynomial.

The definition of treatment and control units based on the size of the firm opens the possibility for firms and workers to self-select into the treatment and control groups in response to the policy. The fixed effects estimator is designed to address issues of endogeneity in the regressors (Lee 2005). Therefore, we estimate equation (3) with a fixed effects estimator for the match (worker $\times$ firm pair). This estimator assumes that the error term $\varepsilon_{i t}=\alpha_{i}+u_{i t}$, where the match unobserved component $\alpha_{i}$ is orthogonal to $X_{i t}$ and $u_{i t}$ is the idiosyncratic error. Given that the wage is a match-specific outcome - the result of the joint characteristics of workers and firms - we decided to use a match fixed effect, but we will also consider firm and worker fixed effects.

\section{$5 \quad$ Wages and employment protection: Quasi-experimental evi- dence}

We take advantage of the 2004 legislative reform that reinforced the two-tier nature of the Portuguese labor market to obtain quasi-experimental evidence on the response of wages. We start by showing that log-wages of treatment and control groups follow a common trend in the before period, validating an identifying assumption. Then, following the insight of Lazear (1990), we show that wages of matches treated decrease due to the tighter employment protection. However, we also show that the impact is strong among new open-ended contracts and fixed-term contracts. Tenured open-ended workers, who benefit directly from the legislation, pay little to nothing in terms of their labor income. As in models of Boeri (2010) and Lindbeck and Snower (2001), the impact on wages differs across workers affected directly by the new legislation and with more bargaining power - tenured open-ended contracts - and those affected indirectly and with less bargaining power - new open-ended and fixed-term contracts.

\subsection{Common trend}

As discussed, a key identifying assumption in the difference-in-differences estimator is the existence of a common trend between treatment and control units in the period before the reform, which is assumed to continue in the absence of the reform. Therefore, before presenting 
our estimates of the causal impact of employment protection on wages, we test this hypothesis.

The existence of a common trend in (log)wages prior to the reform can be formally tested with the following model:

$$
y_{i t}=\theta_{1} \text { Treat }_{i t}+\theta_{2} \text { Time }_{t}+\theta_{3} \text { Treat }_{i t} \text { Time }_{t}+X_{i t} \Phi+\varepsilon_{i t},
$$

where the dependent variable and the independent variables are as in equation (3) and Time $_{t}$ is a linear time trend. The interaction term, Treat $_{i t} \times$ Time $_{t}$, identifies the change in the difference of log-wages over time between treatment and control matches. If the common trend assumption holds, then $\theta_{3}$ should be statistically non-significant.

The estimates of $\theta_{1}-\theta_{3}$ are presented in Table 2. For the before period, 2002 and 2003, we reject the existence of a different growth path of log-wages across treatment and control firms. For the four measures of wages - base and total wages, in monthly and hourly terms - the coefficients on Treat $_{i t} \times$ Time $_{t}$ are all statistically non-significant and economically quite small (between -0.07 and 0.06 percentage points). These results, despite the short time span of the analysis, are reassuring for our identification strategy. The choice of the firm size in the control group was made to guarantee a common trend. Expanding the firm size in the control group leads us, in some cases, to reject a common trend in log-wages across treatment and control units.

[TABLE 2 (see page 22)]

\subsection{Average treatment effect on the wages of the treated}

\section{Are the mandate benefits paid with lower wages?}

Following Lazear (1990), we expect that firms will pass on to workers (part of) the higher firing costs. We test this hypothesis in the quasi-experimental setting, expecting $\psi_{3}$ in equation (3) to be negative. The first panel of Table 3 presents the results for all contracts. The impact on wages is rather uniform across the different wage measures - a decrease of around 0.30 percentage points - although slightly larger for hourly measures (base and total wages per hour). The new legislation caused treated firms to decrease wages relatively to what would have been their behavior had there not been an increase in firing costs. These results are compatible with an inward shift in labor demand and reinforced with an outward shift in labor 
supply.

[TABLE 3 (see page 23)]

Martins (2009) studies a similar reform in Portugal, that took place in 1989, but uses firm-level data. This reform exempted smaller firms, with less than 21 workers, from the job protection procedural rules listed before. Martins (2009) finds that small-firm average wages decreased relatively to larger firms, with higher levels of protection, and rationalizes the result with a fall in bargaining power of workers in smaller firms. In our case, firms bargaining power seem to outweighs any increase in the worker's bargaining power. In fact, our result is perfectly coherent with the predictions of Lazear (1990) and Boeri (2010).

\section{But who pays for the protection?}

Although the legislation applied exclusively to workers on open-ended contracts, it is plausible that firms may have spread the costs among all workers (Boeri 2010). This generates a spillover effect from open-ended to fixed-term contracts. Additionally, existing open-ended contracts may be shielded from a direct impact of the reform due to nominal wage rigidities and explicit contractual arrangements. This behavior of wages is consistent with insider-outsider theories (Lindbeck and Snower 2001). In these models, employment protection strengthens workers' bargaining position and prevents wages of incumbent workers from falling. Arguably, new open-ended matches compete with fixed-term contracts, not with more tenured permanent positions.

To test for differentiated impacts by contract, we split the sample into workers on openended contracts and workers on fixed-term contracts. However, the group of workers on openended contracts maybe quite heterogeneous. Labor market incumbents are tenured open-ended workers. Movers, in the form of new open-ended contracts, should not be seen as workers with high bargaining power. We split the open-ended contracts into low-tenured (up to 36 months) and high-tenured (more than 36 months). The first group is meant to capture the flow of new jobs on open-ended contracts - the movers, which compete directly with the flow of fixed-term contracts. The magnitude and statistical significance of $\psi_{3}$ shall inform us on the relative burden supported by the three groups of workers.

New contracts have lower wages than they would have had in the absence of the increase in employment protection, regardless of the type of contract (last two panel of Table 3). However, 
there is no impact on wages of existing open-ended contracts - the incumbents (second panel). This is true for all four measures of the wage. For instance, total wages of fixed-term contracts are 0.51 percentage points lower, while for new open-ended contracts the fall is close to 0.84 percentage points. These results suggest that firms adjusted wages on the flow of entry jobs, either new permanent jobs or fixed-term contracts (note that most new jobs are actually fixedterm contracts). Incumbents were shielded from this process. Total wages of more tenured open-ended contracts did not change. Firms may face difficulties in adjusting the wage level of existing open-ended contracts due to explicit or even implicit contractual arrangements.

Overall, these results confirm the two-tier model predictions. Incumbents are shielded from the adjustment process. They do not pay for their own extended protection. Thus, the wage premium of permanent employment increases relatively to temporary employment. However, this is not true for the new generation of open-ended contracts, for whom wages are lower due to the extended protection. However, the wage penalty on this type of contracts is not larger than that for fixed-term worker, who do not gain any extra protection with the reform.

\section{Heterogeneity}

Often, policies that apply equally to all workers have differentiated impacts. The margin of adjustment may vary depending on key productive characteristics such as the skill level or the sector of activity. Labor supply elasticities differ across labor market groups, for instance between male and female workers, which will generate different impacts to the policy change. Another source of heterogeneity may arise from the bargaining power of workers, arguably higher for older and white collar workers. Employment protection disproportionately protect workers with higher tenure and higher wages. These workers have a higher incentive to litigate. In this section, we explore these sources of heterogeneity. For the sake of brevity and given the similarity of the results hitherto for the different wage measures, we concentrate on the total monthly wage. This wage measure captures all the wage adjustment mechanisms of firms and it is not affected by adjustment in hours of work.

\section{Age}

The results by age show that young workers in new contracts suffer larger wage losses. The impact is larger for new open-ended contracts, a wage loss of 0.93 percentage points, that 
compare with a wage loss of 0.65 percentage points for fixed-term contracts (columns (1)-(2) of Table 4). The larger wage penalty for young workers under new open-ended contracts is fully consistent with the future higher expected costs of layoffs for these workers.

Wage losses are not confined to young workers. Older workers on new open-ended contracts also experience wage losses. On the contrary, incumbents, both young and old, are shielded from the costs of protection. The impact on wages of the mandated employment protection is non-significant in both cases.

[TABLE 4 (see page 24)]

\section{Gender}

The results by gender presented in Table 4 in columns (3) and (4) have two clear outcomes. First, the reductions in wages are stronger for male workers, particularly among those with new open-ended contracts and fixed-term contracts, where the losses are close or exceed one percentage point. The wage reduction for older open-ended contracts is much smaller, slightly above 0.25 percentage points, but statistically significant. Second, the results for females are quite different. For females there are small positive impacts for existing contracts, while for new contracts there is not significant impact.

These results are consistent with a larger labor supply elasticity for female workers, as in Blundell and MaCurdy (1999) and find support in Bertola, Blau and Kahn (2002) model, which shows employment protection having the largest effects on the wages of workers with inelastic supply.

\section{Manufacturing, construction, and services}

Open-ended contracts are more common in manufacturing firms, where specific human capital tends to have a more important role than in the services sector. Organized labor is also more common among manufacturing firms, where unions have a long history of participation. The differences in production processes across sectors lead to differentiated personnel policies - for instance, in terms of turnover rates and the incidence of temporary contracts. In columns (3)-(5) of Table 4, we split our sample into three sectors: manufacturing, construction, and services.

The results show a substantial degree of heterogeneity across sectors. The largest impact 
occurs by far in the construction sector; wage losses due to the more stringent employment protection are larger than 1.5 percentage points for new contracts and 0.7 for older open-ended contracts. In the services sector, the impacts estimated are still large but they do not exceed -0.7 percentage points for new contracts. In the manufacturing sector, the point estimates are statistically significant only for new open-ended contracts.

These results seem to reflect the varying degrees of flexibility across sectors. Centeno and Novo (2012) show that construction has the higher turnover rate, reflecting the inherent temporary characteristics of construction projects. In the manufacturing sector, contracts tend to last longer and collective bargaining is also higher due to stronger union representation. The differences in specific human capital across sectors may also explain why losses vary. We observe stronger downward adjustments in sectors where specific human capital is typically less important, say services. The high rotation of workers in the construction and services sectors allows also for a larger wage adjustment.

\section{Blue- and white-collar matches}

White collar workers tend to be more tenured and to have higher bargaining power. But high tenure implies a larger increase in the expected costs of lay-off. The results show that, consistent with their lower bargaining power, new open-ended contracts for blue collar workers have a larger wage loss. But, incumbent white-collar workers observe a large wage loss.

The results for blue-collar workers on fixed-term contracts are not statistically significant for total wages but they are much larger for the base wage measures (not shown in the Table).

The type of employment protection introduced in the reform studied here increased the expected cost of employing high-tenured and high-wage workers - mostly white-collar workers. These are expected to suffer the largest impact of the policy. The wage loss of high-tenured white collar jobs may reflect this effect. Furthermore, the increase in employment protection for more tenured workers may have shifted the demand away of these workers into workers who are close substitutes, but have low wages and shorter tenures. This may explain the absence of wage losses for new contracts (both open-ended and fixed-term contracts) of white collar workers.

Overall, new open-ended contract borne the larger wage losses in all groups analysed. This result seems to reflect the highest expected costs of lay-off of the new contracts and the larger bargaining power of incumbent workers. The absence of wage falls (or smaller wage reductions) 
for more tenured open-ended contracts may reflect the nominal wage rigidity that is usually associated with the workings of internal labor markets in firms. Fixed-term contracts share part of the cost of the policy, without any gain in terms of protection. Another detrimental effect of the same reform for workers with fixed-term contracts is the evidence of lower conversion rate reported in Centeno and Novo (2012).

\section{$7 \quad$ Endogeneity of treatment responses and robustness}

The thresholds included in the legislation create the possibility for firms and workers to selfselect into (or out of) treatment. Whereas the inclusion of match-specific effects may go some way into solving endogeneity problems, it is, nonetheless, informative to redefine treatment and control groups and even the sample under analysis to assess the sensitivity of our results to potential sources of bias.

In this section, we look at the endogeneity of treatment responses coming separately from firms and workers. Table 5 address these potential sources of bias. We also perform a falsification exercise using a placebo treatment group, defined at a fake firm-size threshold.

[TABLE 5 (see page 25)]

\section{Firm's self-selection}

The identification of the causal effect is threatened by the possibility that firms sort around the 11- and 20-worker thresholds. The usage of match fixed effects controls for all time-invariant unobserved factors that may affect the propensity of firms and workers to self-select into (or out of) treatment.

If low productivity firms may have kept their size just below the 20 workers threshold to avoid strict employment protection rules, a negative association between wages and employment protection cannot be interpreted as causal. Also, firms at the lower threshold (11 workers) after the reform, may decide to reduce their workforce in order to continue eligible to the simpler dismissal rules. Column (A) in Table 5 presents the estimates of the full sample with firm fixed-effects. The impacts computed with firm fixed-effects are more negative than the ones obtained with match fixed-effects.

In column (B), we set the treatment status in the before period and keep it unchanged in the after period, even if firms changed size. This sample excludes new firms from 2004 onwards, 
but keeps the treatment and control groups unaffected by firms' sorting decisions. Although, the point estimates are lower than in the baseline sample, specially for fixed-term contracts, qualitatively the results are the same - a wage reduction for new contracts and no impact in existing open-ended contracts.

In column (C), we exclude from the sample firms that moved between treatment and control groups. This option allows for firm entry in the post-reform period. The results do not change much, with the exception of older open-ended contracts for which there are now wage losses.

The behavior of firms close to the size thresholds may be of concern, as they may strategically choose a smaller size to avoid additional procedural firing costs. To control for such behavior, we remove from the data firms clustered around each period's threshold (column (D)). In particular, in the before period, with a 20 -worker threshold, firms with 18-25 workers are not considered and, in the after period, with a 10-worker threshold, firms with 11 or 12 workers are excluded. Again, all point estimates are in the range reported hitherto.

\section{Workers's self-selection}

Workers may also non-randomly sort around the thresholds. They may be able to choose their own employment protection regime, moving between firms with a specific size. As with firms, if less productive workers apply to more protected jobs, a negative association between wages and employment protection cannot be interpreted as the causal effect of employment protection on wages.

The worker fixed effects estimator may control for these selection events. The results presented in column (E) of Table 5 are in the range discussed for match fixed-effects, although with a smaller impact for new open-ended contracts and fixed-term contracts.

As we did with firms, in column (F), we consider a sample of workers who never changed treatment status. The results obtained are larger than in our baseline sample for older openended contracts and for fixed-term contracts. This is probably expected. Take workers that move across these firms, they probably do it to avoid wages losses. Thus, once these workers are excluded from the sample, the impact of the new legislation is larger.

\section{Falsification test}

In the final column of Table 5, we perform a placebo test using as treatment group the set of firms with 21 to 30 workers and as control group firms with 31 to 50 workers (this is done year- 
by-year as in table 3). The results are reassuring as all coefficients of interest are insignificant.

All alternative definitions for the sample are fraught with shortcomings, arising from the fact that they are selected samples of the targeted population. However, our point estimates of the causal effect are robust to these new definitions. Our choice of the match fixed effects estimator seems conservative in that the magnitude of the estimated impact is smaller than with other estimators.

\section{Conclusions}

Wages adjust downwards to more stringent mandated employment protection. The causal evidence gathered shows that workers pay the extra protection in the form of lower wages. A finding compatible with an inward shift in labor demand - higher expected costs for employers - but also with a labor supply outward shift - the value to workers of the additional protection.

The main findings in our paper are the large wage loss of new contracts, and the absence of losses in the wage level for incumbent workers and the large spillover effect that the increased protection of open-ended contracts had on wages of workers on fixed-term contracts. This result highlights the strong segmentation of the Portuguese labor market and the channels of wage flexibility introduced by new contracts, in particular fixed-term contracts. Fixed-term workers lose in both dimensions. This generates a wage premium and is consistent with the reduced role of wages as an incentive for these workers, whose probability of entering a longterm relationship with the firm is quite reduced (less than 15 percent of these contracts are converted into a permanent one).

The overwhelming evidence that employment protection decreases wages and increases the wage gap between open-ended and fixed-term contracts is in line with most search and flow models (Boeri 2010). However, these results are in contradiction with the argument in Blanchard and Portugal (2001). Their flow model implies that employment protection raises wages by increasing workers' bargaining power. The reason for this failure is the incapacity of their model to capture the nature of flows in two-tier labor markets. As the results in Centeno and Novo (2012) show, segmented labor markets are not characterized by a low level of churning, but instead by a highly asymmetric distribution of churning rates between open-ended and fixed-term contracts. The rapid adjustment of wages to the increase in employment protection is the price complement to the flows adjustment; higher churning, lower wages, confirming the 
high substitutability between the two contracts.

The previous finding that fixed-term workers bear most of the adjustment cost with higher churning rates (Centeno and Novo 2012) is complemented with evidence that they also suffer the larger wage drops. This result is not a full evaluation of the costs and benefits of employment protection as we do not tackle the potential welfare benefits of more secure job positions. But we do know that this legal protection does come at a cost.

The evidence available for other countries is mixed. For the U.S., Autor, Donohue III and Schwab (2006) find no evidence of an impact on wages of wrongful-discharge laws, and Leonardi and Pica (2010) find a negative impact of an increase in severance payments, exploring a reform of the Italian Labor Code that extended severance payments to firm with fewer than 15 workers. However, these estimates apply to all workers equally, limiting their usefulness to understand what is the impact of employment protection in two-tier labor markets. 


\section{References}

Abowd, J., Corbel, P. and Kramarz, F. (1999), 'The entry and exit of workers and the growth of employment: An analysis of French establishments', Review of Economics and Statistics 81(2), 170-187.

Angrist, J. D. and Pischke, J.-S. (2009), Mostly Harmless Econometrics: An Empiricist's Companion, Princeton University Press.

Autor, D., Donohue III, J. and Schwab, S. (2006), 'The cost of wrongful-discharge laws', Review of Economics and Statistics 88, 211-231.

Bentolila, S., Cahuc, P., Dolado, J. and Le Barbanchon, T. (2010), Two-tier labor markets in the Great Recession: France vs. Spain, Discussion paper 5340, IZA.

Bertola, G., Blau, F. and Kahn, L. (2002), Labor market institutions and demographic employment patterns, Technical Report 9043, National Bureau of Economic Research.

Blanchard, O. and Portugal, J. (2001), 'What hides behind an unemployment rate: Comparing Portuguese and U.S. labor markets', American Economic Review 91(1), 187-207.

Blundell, R. and MaCurdy, T. (1999), 'Labor supply: A review of alternative approaches', Handbook of labor economics 3, 1559-1695.

Boeri, T. (2010), Institutional reforms in European labor markets, in O. Ashenfelter and D. Card, eds, 'Handbook of Labor Economics', Vol. 4, North-Holland, Amsterdam, pp. 11731236.

Burgess, S., Lane, J. and Stevens, D. (2001), 'Churning dynamics: An analysis of hires and separations at the employer level', Labour Economics 8(1), 1-14.

Cabral, L. and Mata, J. (2003), 'On the evolution of the firm size distribution: Facts and theory', American Economic Review 93(4), 1075-1090.

Cahuc, P., Charlot, O. and Malherbet, F. (2012), Explaining the spread of temporary jobs and its impact on labor turnover, mimeo, CREST-ENSAE, École Polytechnique.

Centeno, M. and Novo, A. (2012), 'Excess worker turnover and fixed-term contracts: Causal evidence in a two-tier system', Labour Economics 19, 320-328. 
Doeringer, P., Piore, M. et al. (1971), Internal labor markets and manpower analysis, Heath Lexington Books.

Kugler, A. and Pica, G. (2008), 'Effects of employment protection on worker and job flows: Evidence from the 1990 Italian reform', Labour Economics 15(1), 78-95.

Lazear, E. (1990), 'Job security provisions and employment', Quarterly Journal of Economics 105(3), 699-726.

Lee, M.-J. (2005), Micro-econometrics for policy, program, and treatment effects, Advanced Texts in Econometrics, Oxford University Press, Oxford.

Leonardi, M. and Pica, G. (2010), Who pays for it? the heterogeneous wage effects of employment protection legislation, Working paper 5335, IZA.

Lindbeck, A. and Snower, D. (2001), 'Insiders versus outsiders', The Journal of Economic Perspectives 15(1), 165-188.

Martins, P. (2009), 'Dismissals for cause: The difference that just eight paragraphs can make', Journal of Labor Economics 27(2), 257-279.

Martins, P. S., Solon, G. and Thomas, J. P. (2012), 'Measuring what employers really do about entry wages over the business cycle', American Economic Journal: Macroeconomics 4, 36-55.

Meyer, B. D. (1995), 'Natural and quasi-experiments in economics', Journal of Business $\mathcal{E}$ Economic Statistics 13, 151-162.

Summers, L. (1989), 'Some simple economics of mandated benefits', The American Economic Review 79(2), 177-183. 


\section{Tables}

Table 1: Summary statistics: Match-level data, 2002-2008

\begin{tabular}{|c|c|c|}
\hline Variable (match level) & Mean & $\begin{array}{c}\text { Std. } \\
\text { Deviation }\end{array}$ \\
\hline Fixed-term contracts (in \%) & 25.8 & 43.8 \\
\hline Base wage & 657.4 & 356.1 \\
\hline Hourly base wage & 4.0 & 2.3 \\
\hline Total wage & 807.8 & 442.2 \\
\hline Hourly total wage & 4.8 & 2.8 \\
\hline Age (in years) & 37.4 & 10.9 \\
\hline \multicolumn{3}{|l|}{ Educational level, percentage of workers with: } \\
\hline 4 or less years & 27.9 & 44.9 \\
\hline $4-6$ years & 23.9 & 42.6 \\
\hline 7-9 years & 20.7 & 40.5 \\
\hline 10-12 years & 17.9 & 38.3 \\
\hline College & 9.6 & 29.5 \\
\hline Females (in \%) & 41.6 & 49.3 \\
\hline Immigrants (in \%) & 4.0 & 19.5 \\
\hline Minimum wage (in \%) & 8.3 & 27.5 \\
\hline Tenure (in months) & 84.1 & 89.5 \\
\hline Firm size (average number of workers) & 25.6 & 11.2 \\
\hline Foreign ownership (in \%) & 3.5 & 18.3 \\
\hline Number of matches & \multicolumn{2}{|c|}{1405800} \\
\hline Number of workers & \multicolumn{2}{|c|}{1302865} \\
\hline Number of firms & \multicolumn{2}{|c|}{56680} \\
\hline Number of observations (matches $\times$ year) & \multicolumn{2}{|c|}{3581305} \\
\hline Open-ended contract & \multicolumn{2}{|c|}{2656122} \\
\hline Fixed-term contract & \multicolumn{2}{|c|}{925183} \\
\hline \multicolumn{3}{|l|}{ Before } \\
\hline Treatment & \multicolumn{2}{|c|}{372770} \\
\hline Control & \multicolumn{2}{|c|}{513638} \\
\hline \multicolumn{3}{|l|}{ After } \\
\hline Treatment & \multicolumn{2}{|c|}{1128155} \\
\hline Control & \multicolumn{2}{|c|}{1566742} \\
\hline
\end{tabular}

Notes: Quadros de Pessoal, match-level values 2002-2008. The "Before" period corresponds to 2002-2003 and the "After" period to 2004-2008. Each period, a treatment match is in a firm with 11 to 20 workers and a control match in a firm with 21 to 50 workers. 
Table 2: Common trend estimation

\begin{tabular}{lcccc}
\hline & \multicolumn{2}{c}{ Base wage } & \multicolumn{2}{c}{ Total wage } \\
& Monthly & Hourly & Monthly & Hourly \\
\hline Treat $\times$ Time & 0.051 & -0.009 & -0.001 & -0.067 \\
& $(0.302)$ & $(0.855)$ & $(0.987)$ & $(0.445)$ \\
Treat & 0.112 & 0.181 & 0.332 & 0.436 \\
& $(0.338)$ & $(0.126)$ & $(0.111)$ & $(0.036)$ \\
Time & 3.501 & 3.481 & 4.096 & 4.021 \\
\multirow{2}{*}{ No of observations } & $(0.000)$ & $(0.000)$ & $(0.000)$ & $(0.000)$ \\
\hline
\end{tabular}

Notes: Match (worker-firm) fixed effects estimates. Values in percentage points with $p$-values in parentheses. The estimation window corresponds to the "before" period, 2002 and 2003. Treatment units identify workers in firm with 11 to 20 workers and a control units workers in firm with 21 to 50 workers. The estimates are computed for all workers. See equation (4) for a list of control variables included in the regressions. 
Table 3: Difference-in-differences estimation

\begin{tabular}{lcccc}
\hline & \multicolumn{2}{c}{ Base wage } & \multicolumn{2}{c}{ Total wage } \\
& Monthly & Hourly & Monthly & Hourly \\
\hline All contracts & -0.289 & -0.317 & -0.272 & -0.308 \\
& $(0.000)$ & $(0.000)$ & $(0.000)$ & $(0.000)$ \\
& \multicolumn{4}{c}{3581305} \\
Open-ended contracts & -0.227 & -0.226 & -0.213 & -0.227 \\
& $(0.000)$ & $(0.000)$ & $(0.000)$ & $(0.000)$ \\
Older open-ended contracts & -0.094 & -0.103 & -0.061 & -0.089 \\
& $(0.015)$ & $(0.009)$ & $(0.343)$ & $(0.167)$ \\
& \multicolumn{4}{c}{1990753} \\
Newer open-ended contracts & -0.623 & -0.707 & -0.843 & -0.885 \\
& $(0.000)$ & $(0.000)$ & $(0.000)$ & $(0.000)$ \\
& & \multicolumn{4}{c}{665369} \\
Fixed-term contracts & -0.644 & -0.735 & -0.508 & -0.537 \\
& $(0.000)$ & $(0.000)$ & $(0.004)$ & $(0.002)$ \\
& & \multicolumn{4}{c}{925183} \\
\hline
\end{tabular}

Notes: Match (worker-firm) fixed effects estimates of the After $\times$ Treat coefficient; values in percentage points with $p$-values in parentheses. The "before" period corresponds to 2002 and 2003; the "after" period to 2004-2008. For each period, treatment units identify workers in firm with 11 to 20 workers and a control units workers in firm with 21 to 50 workers. The estimates are computed for four samples: for all workers; workers with open-ended contracts with tenure exceeding 36 months "Older open-ended contracts"; workers with open-ended contracts with tenure not exceeding 36 months "Newer open-ended contracts"; and workers with fixed-term contracts. Besides the treatment variables, the control variables included in the regressions are: (i) Dummy variable for minimum wage earners; (ii) Female indicator; (iii) Quadratic polynomial in (log) age; (iv) Quadratic polynomial in (log) tenure months; (v) Immigrant indicator; (vi) Educational attainment indicators: (a) 4-6 years, (b) 7-9 years, (c) 10-12 years, and (d) college degree. Workers with 4 or less years of schooling are the reference group; (vii) Foreign ownership majority indicator; (viii) Log firm size measured by the number of workers; (ix) Firm age dummies: $1,2, \ldots, 10,11-15,16-20$ years, with the reference group, 21 or more years; (x) District indicators; and (xi) sector of activity (at 2-digits) indicators. 


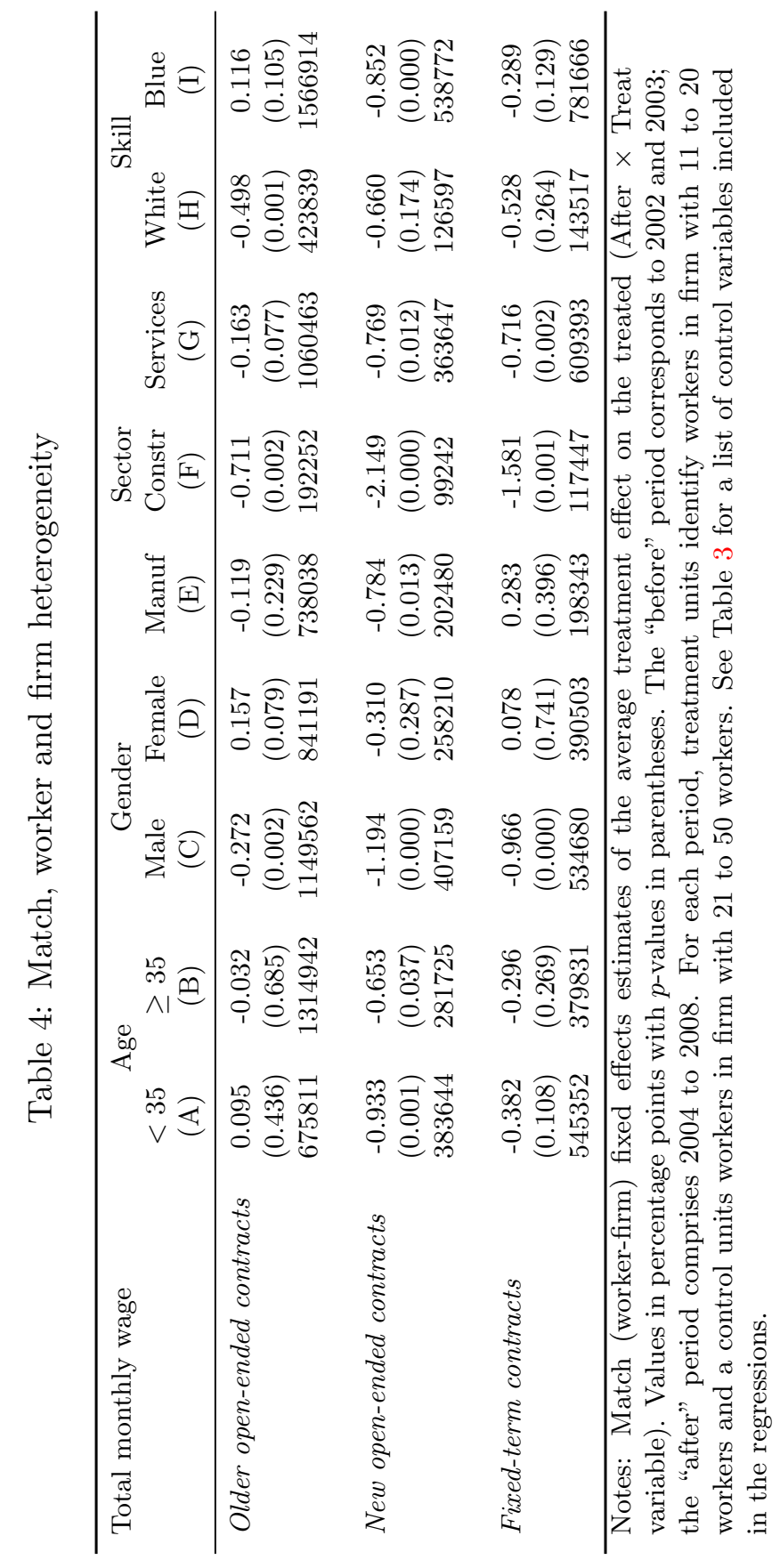




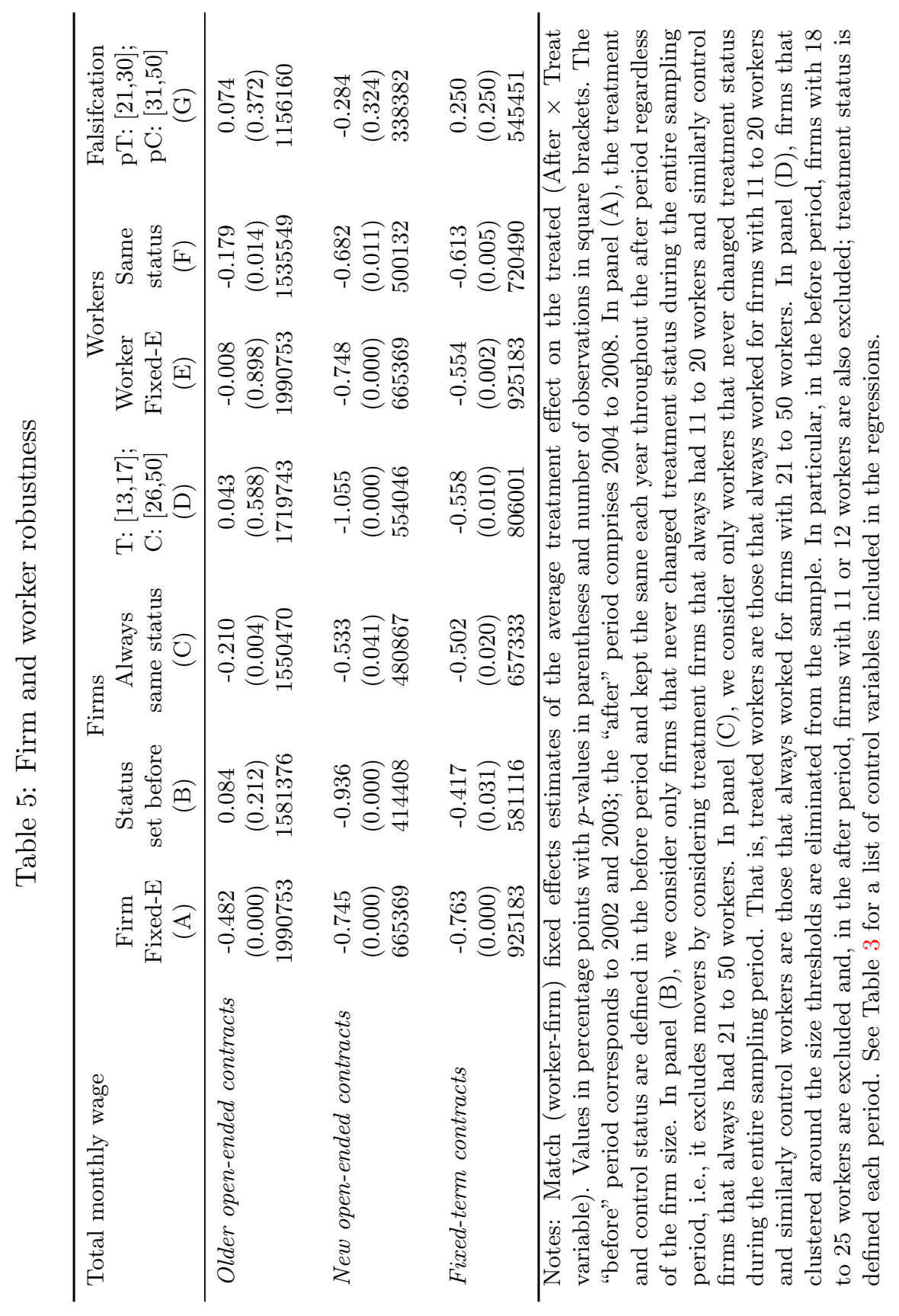

